\title{
EFFECTS OF VARYING FRICTION COEFFICIENT ON ROLLING PRESSURE DISTRIBUTION
}

\author{
F. Davis, ${ }^{l}$ A. Andrews, ${ }^{2}$ M. N. Sackey ${ }^{l}$ and S. P. Owusu-Ofori ${ }^{3}$ \\ ${ }^{I}$ Department of Mechanical Engineering, KNUST, Kumasi \\ ${ }^{2}$ Department of Materials Engineering, KNUST, Kumasi \\ ${ }^{3}$ Department of Mechanical Engineering, North Carolina A\&T State University, Greensboro, \\ North Carolina, USA \\ Correspondingauthor:fkdav@yahoo.com
}

\begin{abstract}
Accurate characteristics of roll pressure distribution is essential in the estimation of the energy and power requirements for parts undergoing plastic deformation. The nature of the pressure distribution is very sensitive to the friction coefficient between the roller and the deformed part. The physics of the deformation process points to a variable friction coefficient, however, current research and practices result in the use of a constant friction coefficient. This work explored the development of a technique to determine a quantitative relationship between the variable friction coefficient and the process parameters. The pressure distribution was then developed within the contact region using the variable friction coefficient model. Results show that current approach used by industry ('the rule of thumb') overestimates the pressure distribution, compared to the current research, thus wasting power needed for the rolling operation by about $18 \%$.
\end{abstract}

Keywords: Rolling, Varying Friction Coefficient, Pressure Distribution, Power

\section{INTRODUCTION}

In order to meet the ever-increasing demand for high quality and low cost products, it is very important to obtain accurate models for the evaluation of process parameters. Since the output of rolling process is almost a finished product, controlling the parameters affecting this process is important. Engineers have to manipulate a lot of parameters such as the speed of deformation, the amount of deformation, the temperature at deformation, lubrication, and material properties in order to achieve a desired outcome in the rolling pro- cess. The goal of this research is to develop a technique to accurately determine the characteristics of the pressure distribution during a rolling process. The determination of the accurate characteristics of pressure distribution within the contact zone is essential for the accurate estimation of the energy and power requirements for the plastic deformation of the part. It has been determined by metal formers that the nature of the pressure distribution is very sensitive to the value of the coefficient of friction between the roller and the deformed part (Beik and Dehghani, 2008). It has also 


\section{Davis et al.}

been determined that the physics of the deformation process points to a variable coefficient of friction between the roller and the part (Murthy and Vadivuchezhian, 2017). Current methods used in the estimation of the friction coefficient within the contact region include experience, rule of thumb, trial and error, and use of empirical formulae. These methods, (Avitzur, 1964, Hill, 1963, Lenard, 2004, Murthy and Vadivuchezhian, 2017, Roberts, 1997, Tieu and Liu, 2004), assume that the friction coefficient is constant within the contact region. An accurate estimation of the friction coefficient leads to a variable value within the contact region. Davis et al., (2017) provided a realistic estimation of instantaneous friction coefficient within the contact region for slab rolling operation. In their study, the "rule of thumb" and other current methods were improved using a new modelling technique where the contact region was incrementally analyzed to obtain the coefficient of friction.
Using the exit thickness as the reference, incremental thicknesses were evaluated using elemental roll angles. The result from the incremental thickness was substituted into a friction coefficient model which is modified to evaluate friction coefficient at each incremental point (Davis et al., 2017). The objective of this work is to develop the pressure distribution within the contact region, assuming a varying friction coefficient from the entry to the exit point and to compare the results with existing models.

\section{ROLLING PRESSURE MODEL}

Fig. 1 shows a model for plastic contact rolling. In this figure, $\mathrm{h}_{0}$ is the initial slab thickness, $h_{f}$ is the final slab thickness, $V_{0}$ is the entry velocity, $V_{f}$ is the exit velocity, $R_{0}$ is the roll radius, $\mathrm{N}$ is the rotational speed of the roll, $V_{r}$ is the roll velocity, and $d \theta$ is the included roll angle for the elemental strip within the deformation zone.

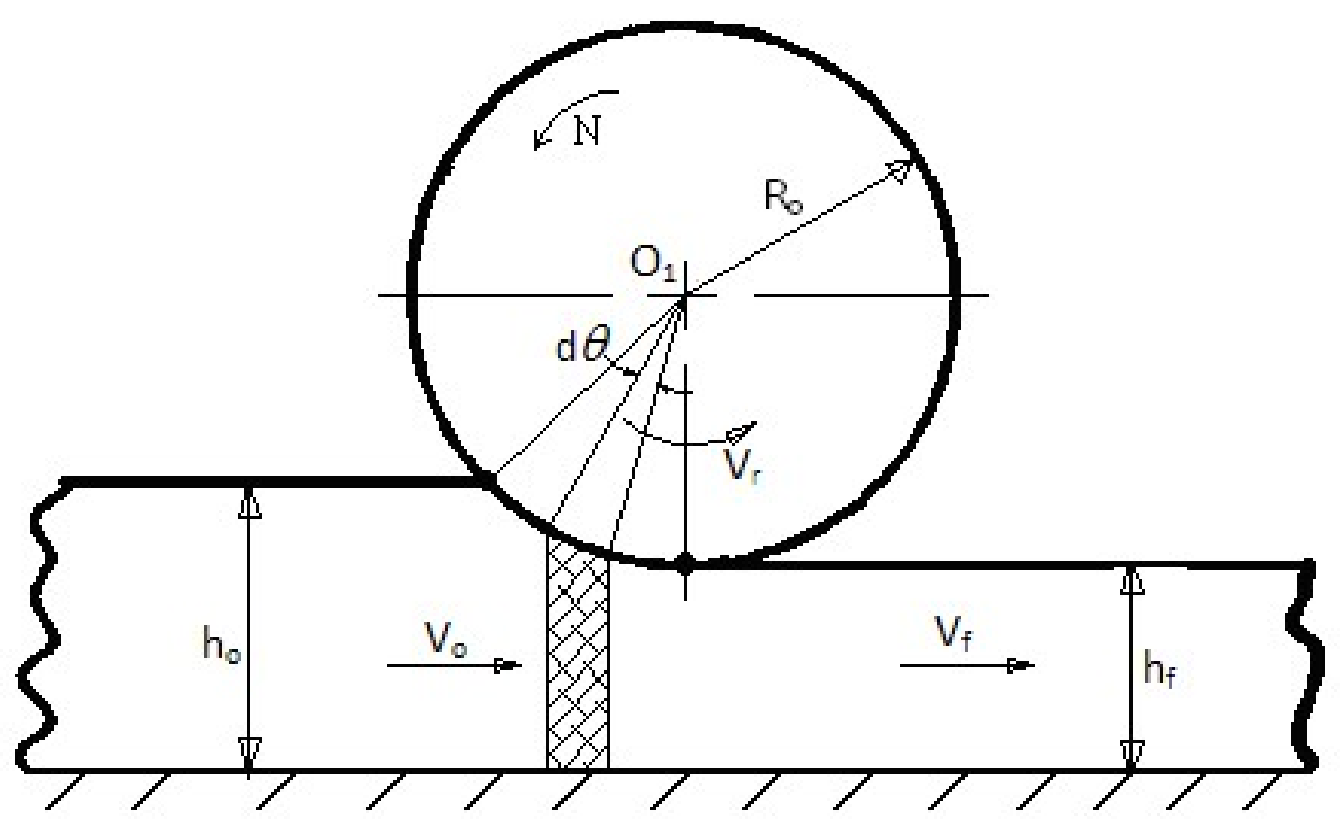

Fig. 1: Plastic rolling contact model 
From Fig. 1, a force analysis on an elemental strip within the contact region results in a stress equation shown in Equation 1. In this equation, $\sigma_{\mathrm{x}}$ is the axial stress, $\mathrm{P}_{\theta}$ is the roll pressure at angle $\theta$, and $\mu_{\theta}$ is the friction coefficient. The stress equation shows a high influence of the frictional coefficient.
Researchers in this field have solved the stress equation with several assumptions. One of the assumptions is that the friction coefficient is constant within the contact region. According to the principles of physics, the magnitude of the friction force between surfaces in contact decreases continuously as it changes from the



To reduce the effects of friction, a second roller could be introduced as shown in Fig. 2. Once again, a force analysis on an elemental strip within the contact region results in a stress equation shown in Equation 2. It can be seen from Equation 2 that the influence of friction has been greatly reduced with the loss of the second term in Equation 1. Equation 2 was first derived by Von Karman (Dieter, 1976). quasi-static to the dynamic modes. The physical behavior of the friction force is illustrated in Fig. 3. In relation to dynamic rolling contact, the friction force between surfaces in contact changes from the part entry point to the exit point. As a result, the friction coefficient should also vary. The relationship between the normal pressure $\mathrm{P}$ and the horizontal compresssive stress $\sigma_{\mathrm{x}}$ in Equation 2 is given by considering the distortion energy criterion of

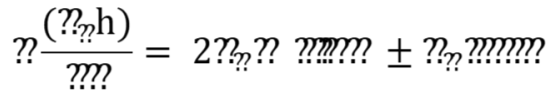

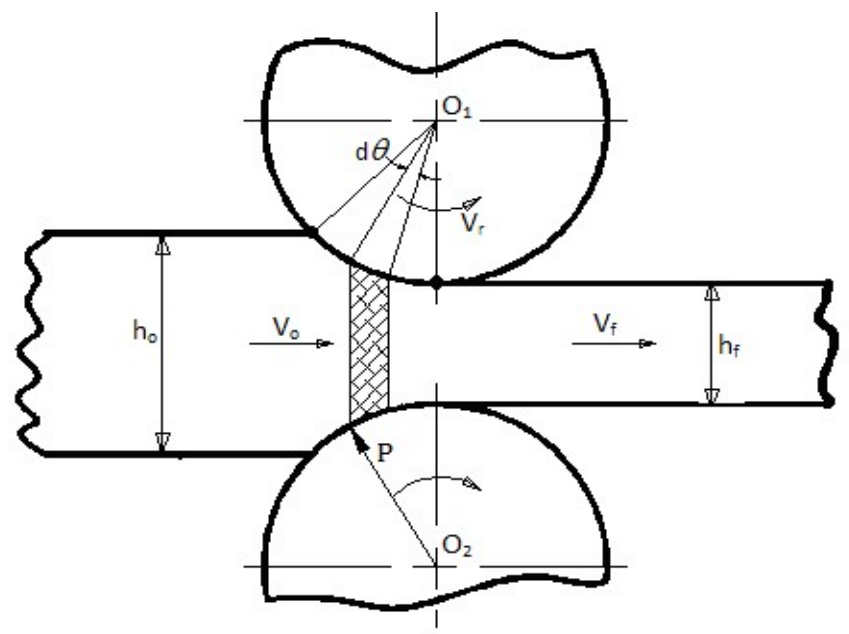

Fig. 2: Double roller plastic rolling contact model 
yielding for the plane strain condition. This is expressed in Equation 3.

$$
\begin{array}{r}
? ?_{1}-? ?_{3}=\frac{2}{\overline{3}} ? ?_{? ?}=2 ? ? \\
=?_{0} \quad \ldots \ldots
\end{array}
$$

Where $\sigma_{1}$ and $\sigma_{3}$ are the principal stresses within the contact zone, and $\sigma_{\mathrm{y}}, \sigma_{0}$, and $\mathrm{K}$ are the yield strength, flow stress, and the shear yield strength of the work material, respectively.

Considering a stress element within the deformation zone as shown in Fig. 4 and assuming that the frictional force is very small and can be neglected, the principal stresses in the element can be evaluated as $\sigma_{1}=\sigma_{x}$ and $\sigma_{3}=-P$. The negative sign accounts for the compressive nature of the stress. Thus equation 3 can be written in terms of $\sigma_{x}$ and $\mathrm{P}$ as shown in equation 4.

$$
? ?+?=2 ? ?
$$

Now, eliminating $\sigma_{\mathrm{x}}$ from Equations 2 and 4 and noting that the friction force changes direction in accordance with the relative speed between the roller and the part results in Equation 5 .

$$
\begin{aligned}
& \text { ?? } \frac{2 ? ?-? ? \mathrm{~h}}{? ? ?}=2 ? ? ? \text { ??m?!? } \\
& \text { 土 ??!?!?!?? }
\end{aligned}
$$



Fig. 3: Friction Coefficient Curve 


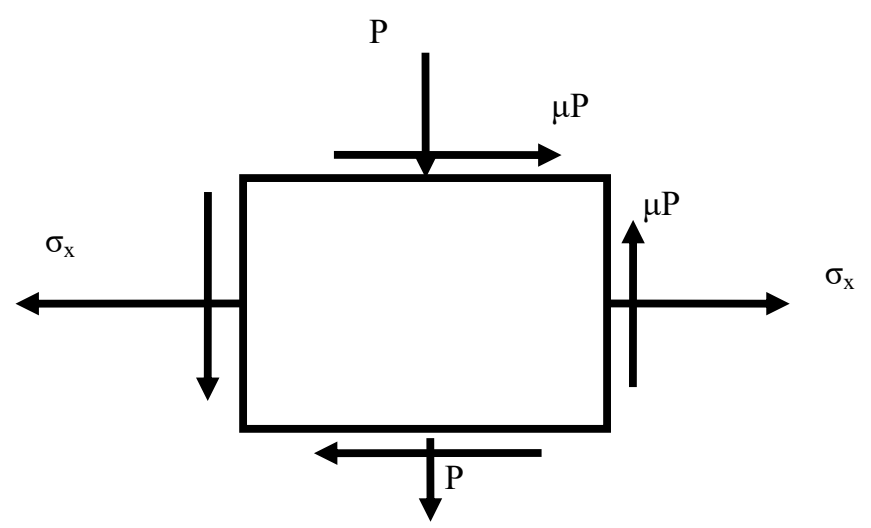

Fig. 4: Stress element in deformation zone

The complexity of Equation 5 makes it necessary to obtain solutions by numerical methods. Some simplification has been suggested by other researchers for the purpose of obtaining a closed-loop solution to Equation 5. The simplifications are that: (1) the coefficient of friction $(\mu)$ is constant at all points on the arc of contact, (2) the angle $\theta$ subtended by the work in the deformation zone is very small, (3) the shear yield strength $(\mathrm{K})$ is constant, and (4) there is an identifiable point where no slip occurs between roller and the part, known as the neutral point. Applying the above simplifications to Equation 5 and integrating, results in Equations 6, 7, and 8. For details of the integration refer to (Gosh and Mallik, 1986).

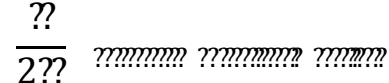

$$
\begin{aligned}
& =\frac{\mathrm{h}}{\mathrm{h}_{0}} \quad 1-\frac{?_{m}}{2 ? ?} \quad ?^{?} ?^{?_{0}-} ?
\end{aligned}
$$

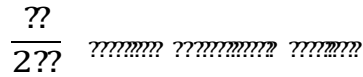

$$
\begin{aligned}
& =\frac{\mathrm{h}}{\mathrm{h}_{?}} \quad 1 \\
& \text { - } \frac{? ? m ? ! ?}{2 ? ?} \eta ? ?
\end{aligned}
$$

$$
\eta=2 \frac{\bar{n}}{\mathrm{~h}_{m}} m m^{1} \quad \frac{\bar{?}}{\mathrm{~h}_{?}} ?
$$

Where, $h_{0}$ and $h_{f}$ represent entry and exit thickness of the deformed part, respectively,

$$
\frac{P}{2 K} \quad \text { represents a non - dimensional roll }
$$

pressure, $\sigma_{x b}$ and $\sigma_{x f}$ represent back and front tensions respectively. The pressure at the neutral point is determined from either Equation 6 or 7 . The value of the parameter $\lambda$ corresponding to the neutral point $\left(\lambda_{n}\right)$ is obtained by equating Equations 6 and 7. The result is shown in Equation 9.

$$
\begin{aligned}
& ?_{?}=\frac{1}{2} \frac{1}{n ?} m \frac{\mathrm{h}_{n}}{\mathrm{~h}_{0}} \frac{1-?_{? ? 0} 2 ? ?}{1-?_{? m ?}^{m} 2 ? ?} \\
& +?_{0}
\end{aligned}
$$


The location of the neutral point $\theta_{\mathrm{n}}$ corresponding to $\lambda_{\mathrm{n}}$ can be obtained from Equation 8. In practice, the estimation of pressure distribution assuming constant friction coefficient has been found to be deficient and results in gross over estimation of the rolling stresses and this leads to inconsistencies in product performance (Tieu and Liu, 2004). This research seeks to improve the accuracy in the estimation of force and pressure distribution and friction hill within the contact region of a rolling cylindrical element on a flat surface. The next section analyzes the pressure distribution within the contact region using varying friction coefficient model (Davis et al., 2017) and also comparing the results with existing models (Avitzur, 1964, Tieu and Liu, 2004).

\section{ANALYSIS OF PRESSURE DISTRIBU- TION}

Pressure distributions were analyzed using the constant friction coefficient approach and the varying friction coefficient models. The constant friction coefficient models considered were the Rule of Thumb, Tieu Model, and Avitzur Model. The varying friction coefficient models considered were SG Roll Experimental Model, Modified Tieu Model, and Modified Avitzur Model (Davis et al., 2017).

\section{Pressure distribution for constant friction coefficient}

For rolling to be accomplished, the friction coefficient between the work and roll interface must be sufficient enough to overcome the roll resistance. Equation 10 provides the physical constraint of the process, where, $\mu$ and $\theta_{\max }$ are friction coefficient and bite angle respectively.

$$
? ?=\tan ? ? ? ? m ? \ldots \ldots \ldots \ldots(10)
$$

From Equation 10, and the input parameters of Tieu, the theoretical friction coefficient was evaluated to be a minimum of 0.085 , while the rule of thumb friction coefficient is normally chosen as 0.1 for a cold-rolling operation (Groover, 2007). Solving Equations 6, 7, 8, 9, using Matlab Software, the variation of pres- sure distribution for a rule of thumb friction coefficient model $(\mu=0.1)$ is provided in Fig. 5 . Friction between the work and roll interface caused the pressure to increase exponentially as the work entered the rolls until the maximum pressure is attained at a location of about 0.026 radians from the exit point. Thereafter, the pressure decreased almost linearly until the work exited the roll.

The coefficient of friction based on Tieu and Avitzur models were estimated (Avitzur, 1964, Tieu and Liu, 2004). The variation of pressure distribution was determined based on these two models and are presented in Figs. 6 and 7. The pressure distribution patterns for the three cases for the constant friction coefficient models were similar with minor differences in the peak pressures and their location. Comparison of the three cases of constant friction coefficient models (Rule of Thumb, Tieu Model, and Avitzur Model) was made. The results are shown together in Fig. 8. It can be seen that as the coefficient of friction increased, the no slip point shifted towards the entry, and the peak pressure increased.

The area under the pressure distribution curves can be shown to be proportional to the power and force required for the rolling operation. Thus, as the friction coefficient increased, the power required in performing the operation increased. The detectable changes in the area under the pressure curves, peak pressures and the location of no-slip point compared with the small changes in friction coefficient values confirmed that the friction coefficient is a very sensitive parameter.

Thus maximum care must be taken in its estimation. It can be said that the Rule of Thumb value which is used in industry leads to an over -estimation according to the Tieu and Avitzur models.

\section{Pressure distribution for varying friction coefficient}

Referring to Fig. 4, the principal stresses are evaluated by considering the fact that the frictional stresses lead to non-negligible shear stresses. Let the principal stresses be $\sigma_{1}, \sigma_{2}$, 
Varying friction coefficient on pressure distribution... 17

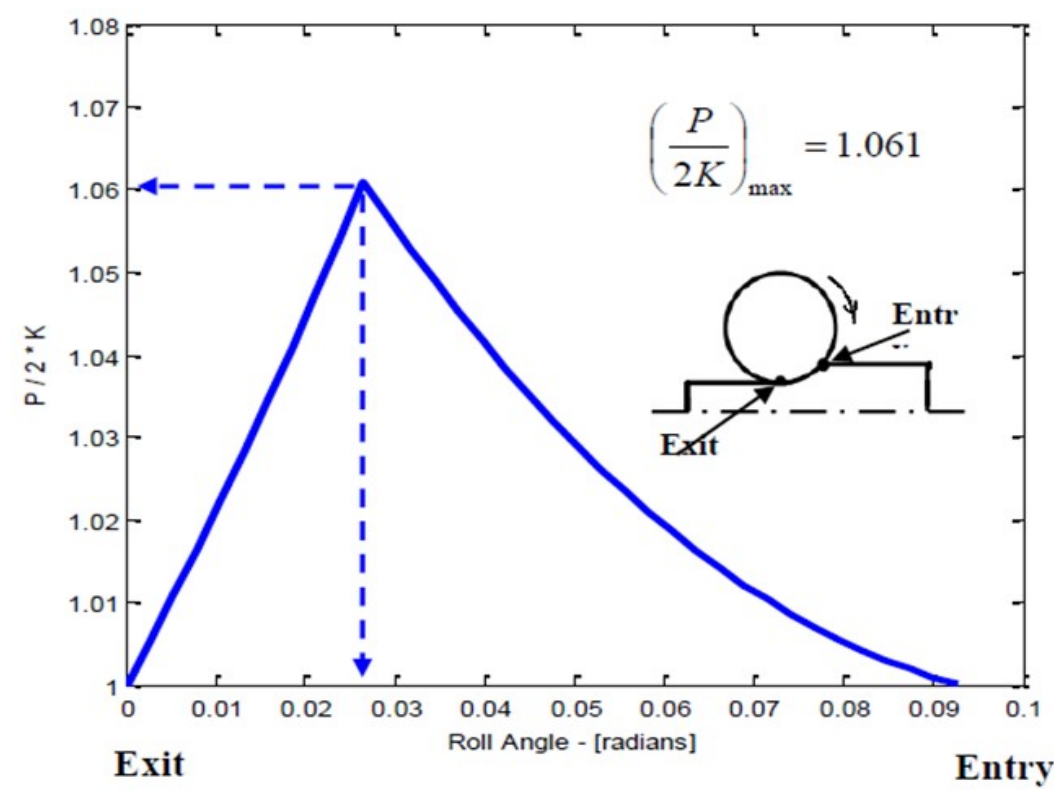

Fig. 5: Variation of pressure distribution - Rule of thumb

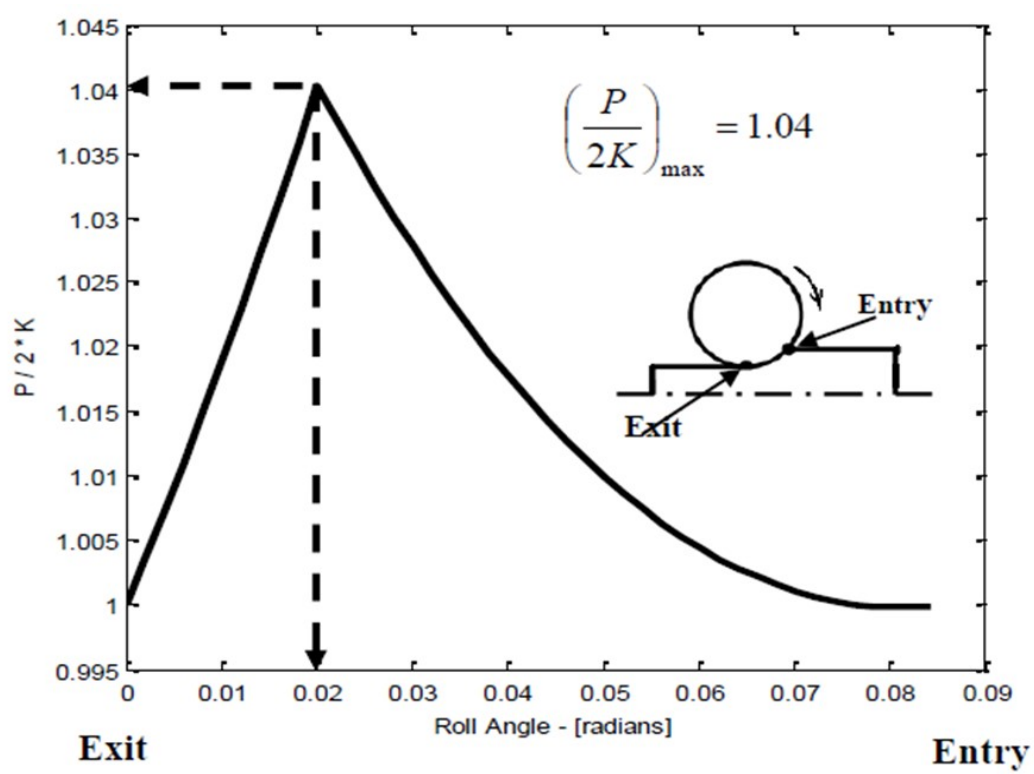

Fig. 6: Variation of pressure distribution - Tieu 


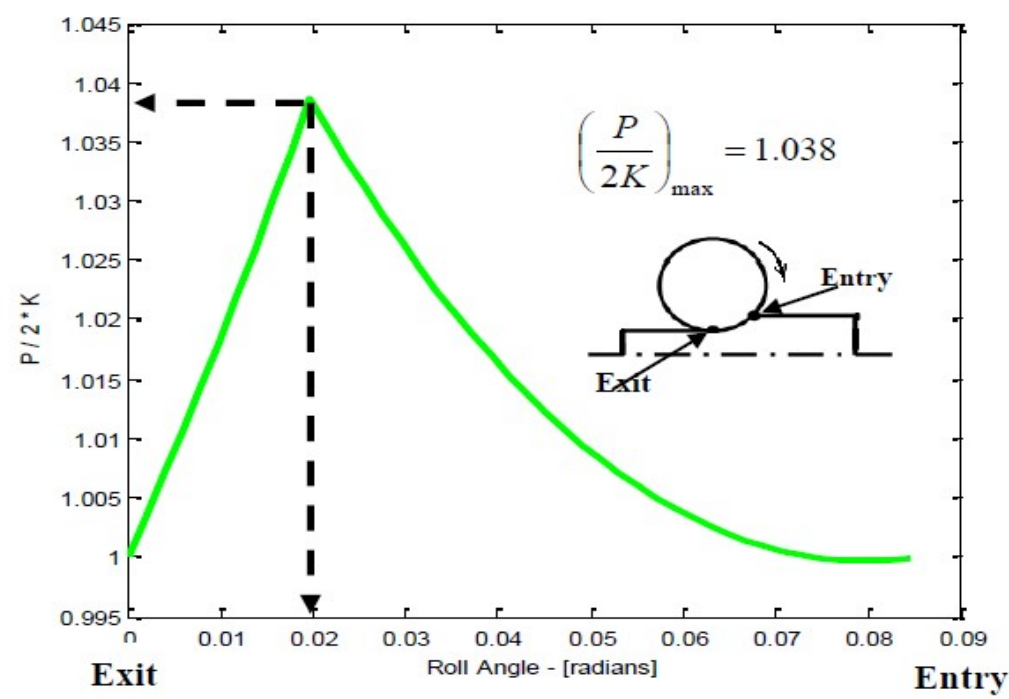

Fig. 7: Variation of pressure distribution - Avitzur

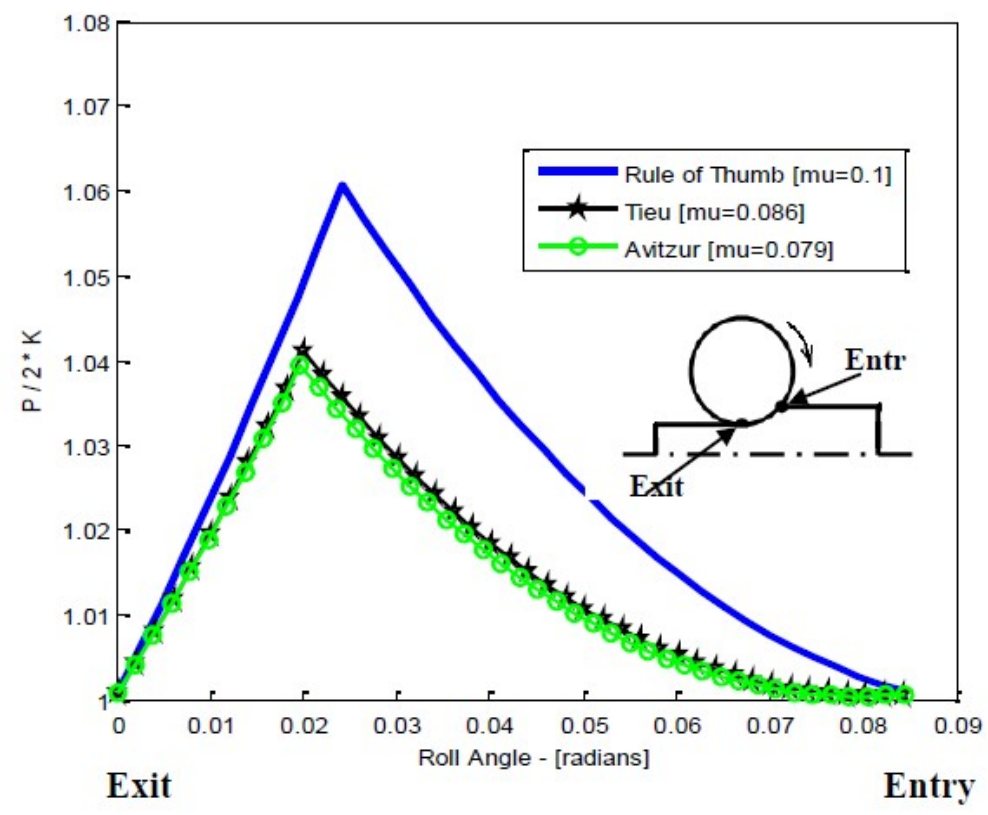

Fig. 8: Comparison of pressure distribution - Constant Friction Models 
and $\sigma_{3}$ respectively.

$$
\begin{aligned}
& ?_{1}=?_{m}+?_{? ? m} \ldots \ldots .(11) \\
& ?_{3}=?_{m}-\quad ?_{? ? m} \ldots \ldots \ldots \ldots(12)
\end{aligned}
$$



$$
\begin{aligned}
& =?_{?}-? m^{2}+m^{2} ?^{2} \frac{1}{2}
\end{aligned}
$$

Now, evaluating $\sigma_{x}$ from the distortion energy criterion of yielding for plane strain condition, by substituting $\sigma_{\mathrm{av}}$ and R into Equations 11, 12, and then further substitution into Equation 3 results in the expression for $\sigma_{\mathrm{x}}$, which is shown in Equation 13.

$$
?_{n}=2 \quad \begin{aligned}
\frac{?}{2}^{2} & -m^{2} 2^{\frac{1}{2}} \\
& -\quad ? \ldots \ldots \ldots \ldots
\end{aligned}
$$

Assuming that the effect of strain hardening on the material is negligible and thus the flow stress $\left(\sigma_{0}\right)$ is constant, and differentiating $\sigma_{\mathrm{x}}$ with respect to $\theta$ results in the expression shown in Equation 14.

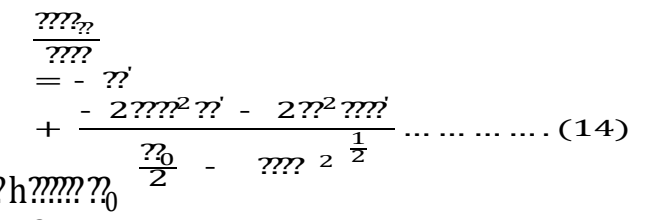

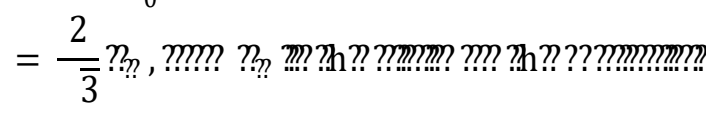

material. Now, rewriting Von Karman's Equation (Equation 2) in another form results in the expression shown in Equation 15.

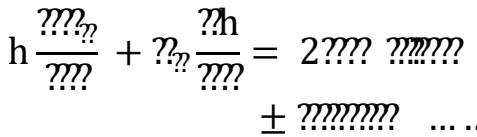

Substitution of the expressions for $\frac{\partial \sigma_{x}}{\partial \theta}$ and

$\sigma_{x}$ into Equation 15 results in the expression shown in Equation 16.

$$
\begin{aligned}
& \text { - ??h - h } \frac{2 ? ? ?^{2} ?^{\prime}+2 ? ?^{2} ? ? ?^{\prime}}{{\frac{?_{0}}{2}}^{2}-m ?^{2^{\frac{1}{2}}}} \\
& +2 \mathrm{~h}{\frac{?_{0}}{2}}^{2}-m m^{2^{\frac{1}{2}}} \\
& \text { - h'? } \\
& \text { = 2??? ??m?? } \\
& \pm ? ? ! ? ! ? ! ? ?
\end{aligned}
$$

Making $P^{\prime}$ the subject of Equation 16, results in the expression shown in Equation 17, where the normal pressure $(\mathrm{P})$ and friction coefficient $(\mu)$ are functions of roll angle $(\theta)$.

Equation 17 is the expression derived for estimating the pressure distribution along the contact length when friction coefficient between the work and roll interface is not assumed to be constant. The complexity of Equation 17 makes it necessary to obtain a solution by numerical methods. Using finite forward difference method to further simplify Equation 17, results in Equations 18.

The minus and plus $( \pm)$ signs in equation 18 occur because the direction of the friction force changes at the no-slip point. The plus sign applies between exit point and the no-slip point, while the minus sign applies between the entrance and the no-slip point. The next paragraphs demonstrate the variation of pressure distribution using three varying friction coefficient models namely SG Roll Experimental, Modified Avitzur, and Modified Tieu Models 


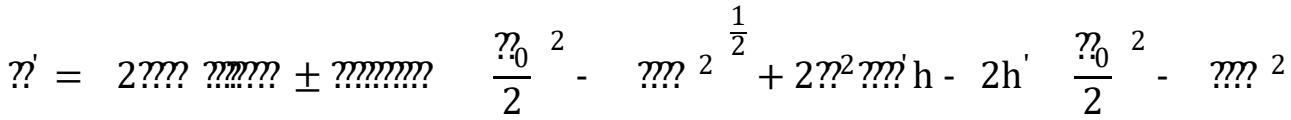

$$
\begin{aligned}
& +h^{\prime} ?{\frac{?_{0}}{2}}^{2}-m ?^{2^{\frac{1}{2}}} \div-\mathrm{h} \frac{?_{0}}{2}-m ?^{2}{ }^{\frac{1}{2}}+2 m ?^{2} \mathrm{~h}
\end{aligned}
$$

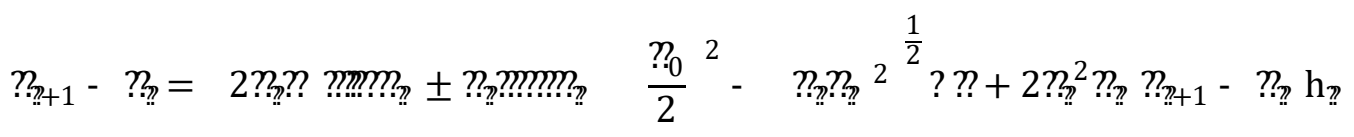

$$
\begin{aligned}
& -2 \mathrm{~h}_{\eta+1}-\mathrm{h}_{?} \quad{\frac{?_{0}}{2}}^{2}-m ?^{2}+\mathrm{h}_{?+1}-\mathrm{h}_{\eta} ?_{?}{\frac{?_{0}}{2}}^{2}-m_{?} 2^{\frac{1}{2}} \\
& \div \mathrm{h}_{?}{\frac{?_{0}}{2}}^{2}-m ? ?^{2^{\frac{1}{2}}}+2 ?_{? ? ? ?} ?_{?}^{2} \mathrm{~h}_{?}
\end{aligned}
$$

developed and presented by Davis et al., (2017).

The SG Roll Experimental friction coefficient is modeled and presented as shown in Equations 19 and 20.

$$
\begin{array}{r}
? m m m m ! m ! \\
=-0.2105 ?^{2}+0.2087 ? ? \\
+0.0606 \ldots \ldots \ldots \ldots
\end{array}
$$

? $m ? m ! m ! ?=0.3077 ?+0.0452$

Now, we illustrate the estimation of pressure distribution using the friction coefficient obtained from the SG Roll Experiment. Solving Equations 18, 19, 20, using Matlab Software, the variation of the pressure distribution using the varying SG Roll Experimental friction coefficient model is determined. This is shown in
Fig. 9.

From Fig. 9, friction and slipping between the part and the roll interface caused the pressure to increase continuously as work entered the roll until a maximum pressure of $P / 2 K=1.044$

was attained at the no-slip point estimated to 0.023 radians from the exit point. A comparison of Figure 5 shows that the no-slip points has shifted slightly toward the exit and the peak pressure is lower than the constant friction coefficient value method. The varying friction coefficient models for the modified Tieu and Avitzur friction coefficient models are shown in Equations 21, 22, 23, and 24, respectively.

Solving Equations 18, 21, 22, 23, 24 using Matlab Software, the variation of the pressure distribution for the Modified Tieu and Avitzur friction coefficient models are shown in Figs. 10 and 11 respectively.

A comparison of the varying friction coefficient models (SG Roll Experimental, Modified Tieu Model, and Modified Avitzur) was made. The result is shown in Fig. 12. The varying friction 


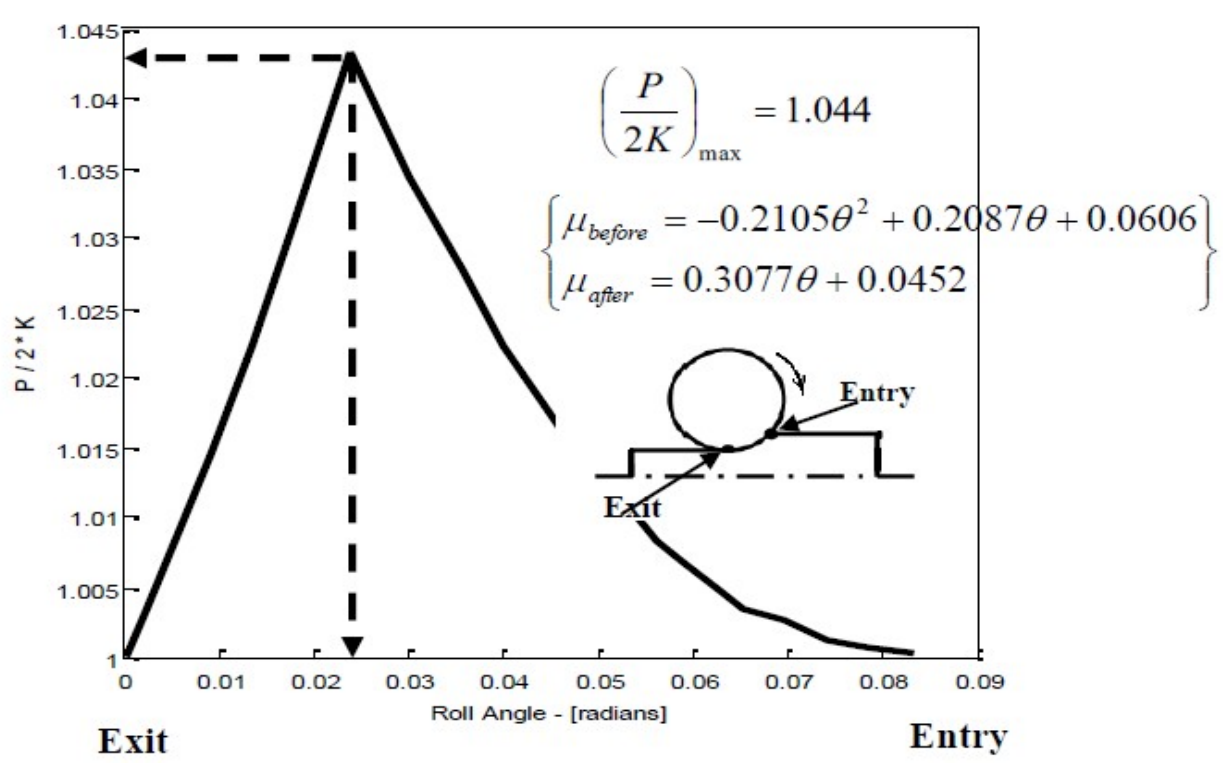

Fig. 9: Variation of pressure distribution - SG Roll Friction Model

$$
\begin{aligned}
& ?_{m m m m m ! n}=10.11 ?^{2}-0.3877 ? \\
& +0.0871 \\
& ?_{m}^{m m m ! m ?}=0.083 \\
& ?^{m} \text { mmm? }=0.8395 ? \\
& +0.1002
\end{aligned}
$$

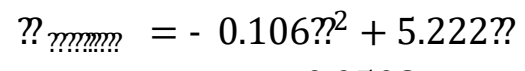

$$
\begin{aligned}
& +0.0508
\end{aligned}
$$

coefficient models showed the same trend and the same shape. The peak pressure for the modified Tieu model was higher than the peak pressures of the modified Avitzur and the measured. The power required for the rolling operation is proportional to the area under the pressure distribution curve. For the same parameters, Tieu's modified model would estimate the highest power requirement.

A comparison of Rule of Thumb, Tieu, Avitzur, Measured, Modified Tieu Model, and Modified Avitzur Model was made. The results are shown in Fig. 13. From Fig. 13, as the coefficient of friction varied; (1) peak pressure changed, (2) area under the pressure distribution curve changed, and (3) the no-slip point shifted. Comparing each model with the experimental results suggests that, the rule of thumb model over-estimates the power requirements while Tieu and Avitzur's models underestimate the power. The under estimated parameters are undesirable in the cold rolling operation because of the following reasons: (1) cold rolling is a finishing operation in metal forming and the product quality could be highly compromised and (2) the life of the rolling equipment may be shortened due to high 


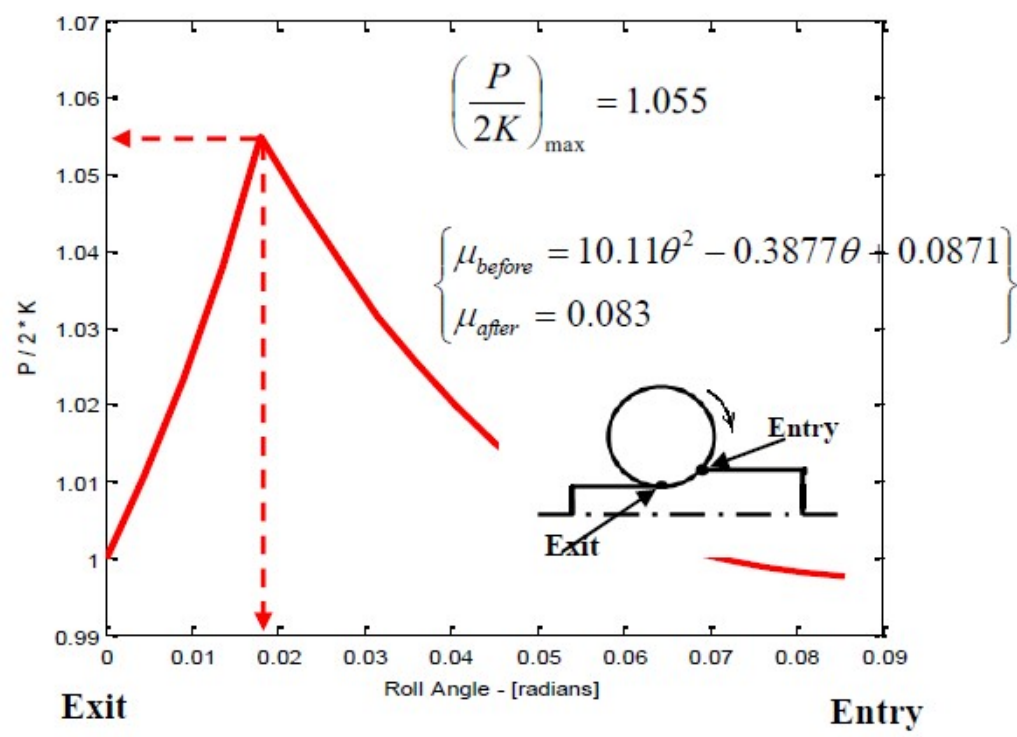

Fig. 10: Variation of pressure distribution - Modified Tieu Model

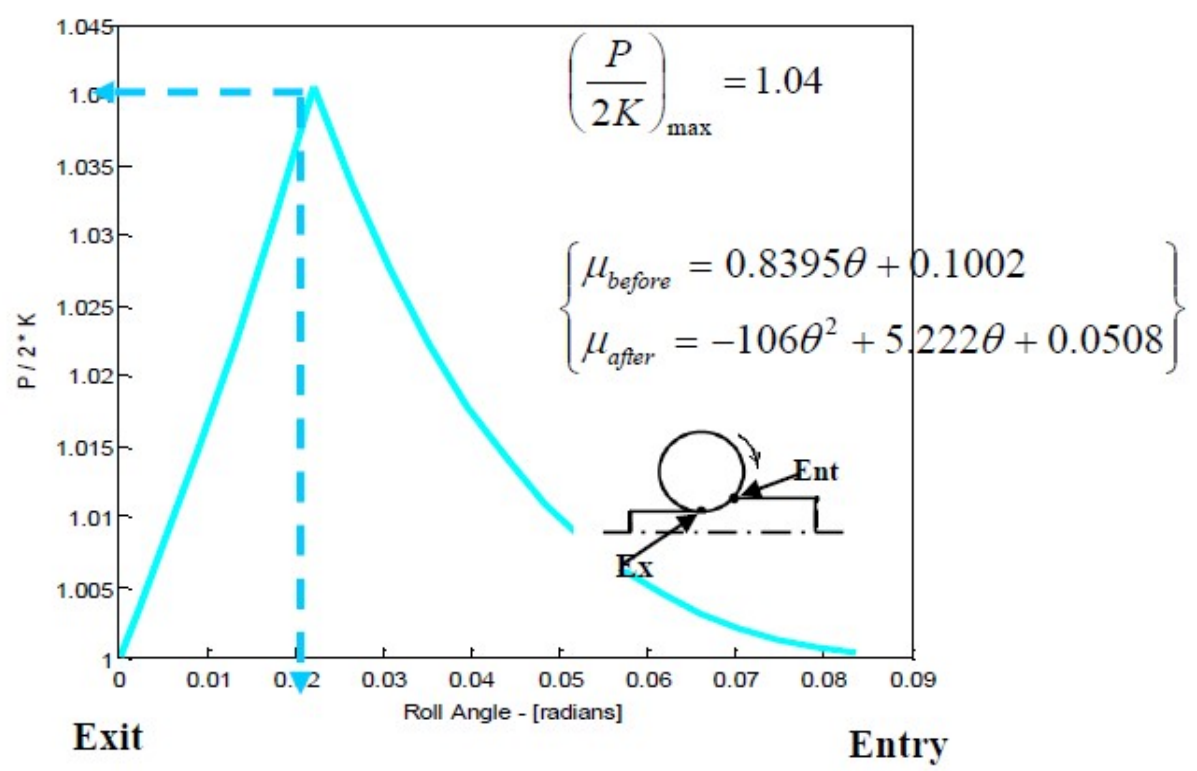

Fig. 11. Variation of pressure distribution - Modified Avitzur Model 
Varying friction coefficient on pressure distribution... 23

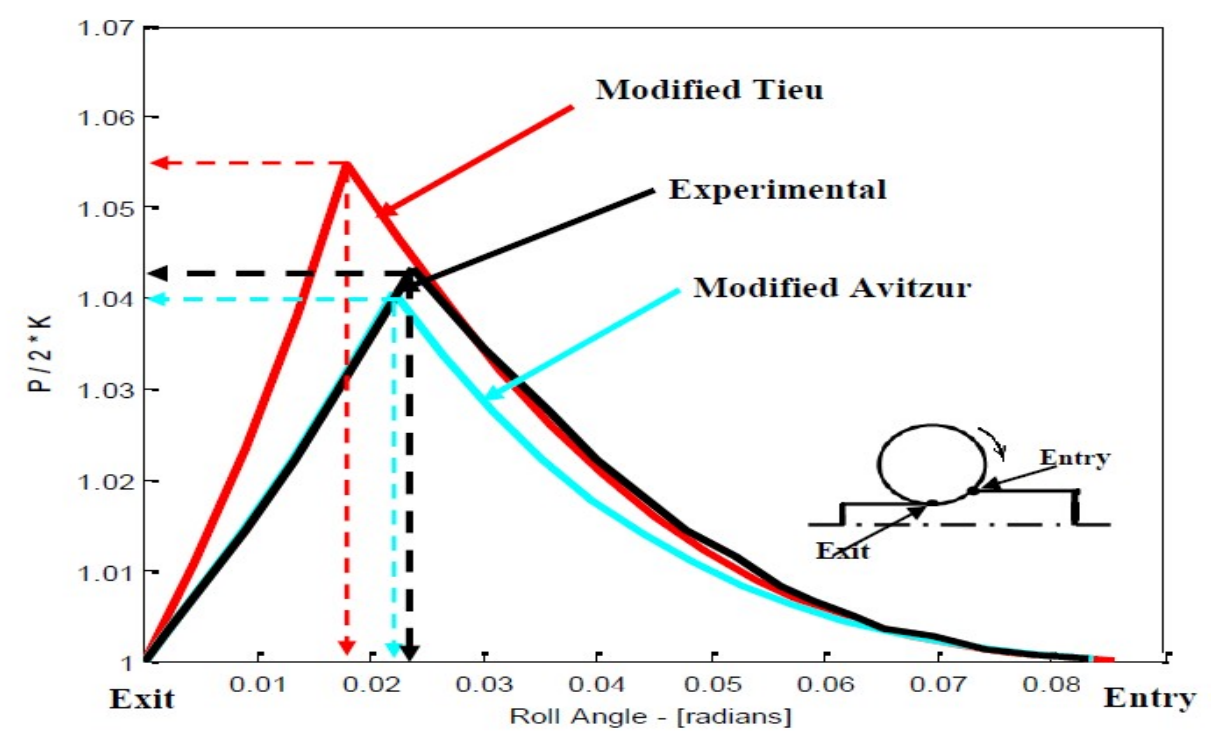

Fig. 12: Comparison of pressure distribution - Modified Models and SG Roll Experimental Data

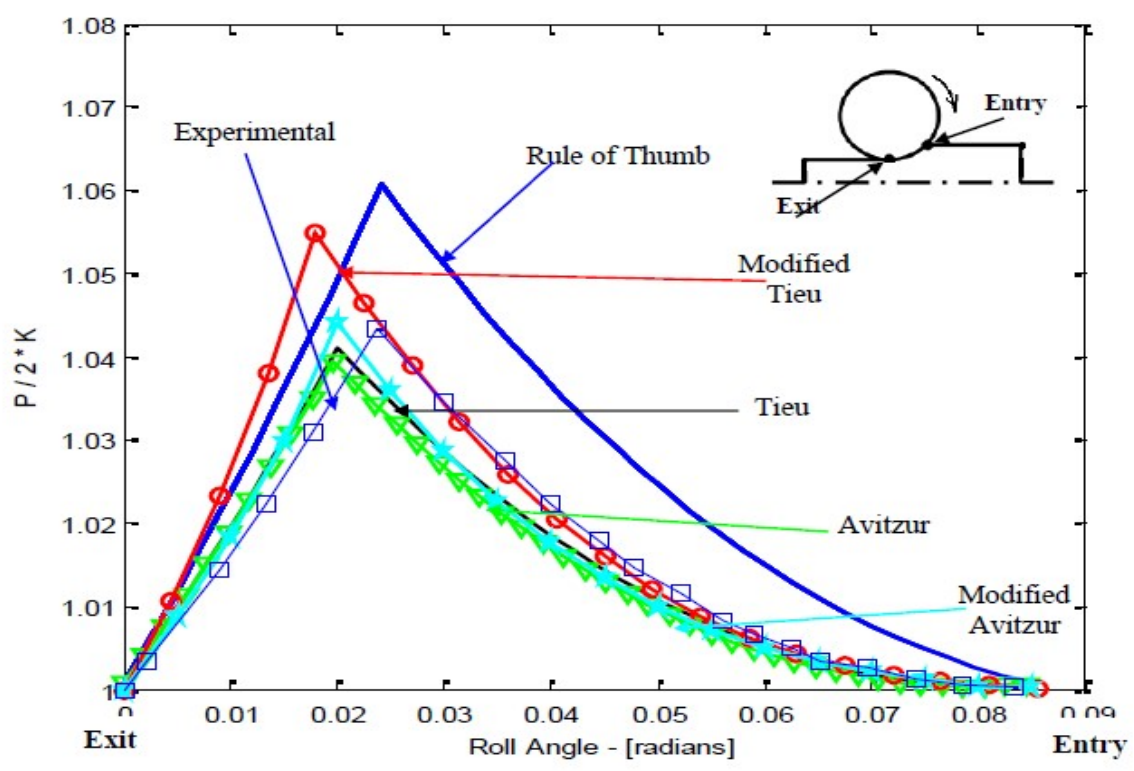

Fig. 13: Comparison of pressure distribution for the various models 
stresses.

Table 1 provides a numerical comparison of the parameters of the pressure distribution. It can be seen that the measured parameters compare most favorably with the Modified Avitzur Model. Their no-slip points are similar, the peak points are essentially equal in magnitude. The area under the curve are close to each other. Their savings in power compared to the rule of thumb model are almost the same. The Modified Avitzur Model resulted in 18\% savings in power compared to the rule of thumb model while the Modified Tieu Model resulted in 16\% savings. Avitzur and Tieu's original models suggest $26 \%$ and $22 \%$ savings in power respectively compared to the rule of thumb model. This savings suggest lesser deformation forces which could be a concern with respect to the dimensional accuracy and precision of the product.

\section{CONCLUSION}

Pressure distribution models have been developed within the contact region using a varying friction coefficient model. The results of this work allows the scientific and the engineering work to realize the importance of applying varying coefficient of friction in the evaluation of the characteristics of the pressures in the contact region during the plastic deformation of a metallic slab. Through this work, the power and energy requirements are determined more accurately than the present methodologies. The following specific conclusions may be drawn from the results obtained in the work.

1. Current industrial practices overestimate the pressures required for the rolling operation. Though this ensures a permanent deformation, it could lead to poor product quality such as cracking.

2. A classical method proposed by Avitzur and an empirical method proposed by Tieu in attempts to improve upon the prediction of the rolling pressure tend to underestimate the pressure distribution from the entry to the no-slip point and overestimate it from the no-slip point to the exit point.

3. There is $16 \%$ to $18 \%$ savings in the rolling power requirement using the varying coefficient of friction modeling techniques over the traditional constant coefficient of friction method.

4. The pressure distribution resulting from the experimental friction coefficient model compares favorably with the modified Tieu model between the entry and the no-

Table 1: Comparison of pressure distribution parameters for various models

\begin{tabular}{|c|c|c|c|c|c|c|}
\hline \multirow[t]{2}{*}{ Parameter } & \multicolumn{3}{|c|}{$\begin{array}{l}\text { Current Approach (Constant } \\
\text { Friction Model) }\end{array}$} & \multicolumn{3}{|c|}{$\begin{array}{l}\text { Based on this Research (Varying Friction } \\
\text { Model) }\end{array}$} \\
\hline & $\begin{array}{l}\text { Rule of } \\
\text { Thumb }\end{array}$ & Tieu & Avitzur & $\begin{array}{l}\text { Modified } \\
\text { Tieu }\end{array}$ & $\begin{array}{l}\text { Modified } \\
\text { Avitzur }\end{array}$ & Experimental \\
\hline $\begin{array}{l}\text { Theta Neutral }\left(\theta_{N}\right) \text { - } \\
\text { Radians }\end{array}$ & 0.0241 & 0.0201 & 0.0196 & 0.0189 & 0.022 & 0.023 \\
\hline Peak - $(\mathrm{P} / 2 * \mathrm{~K})$ & 1.061 & 1.041 & 1.039 & 1.055 & 1.04 & 1.044 \\
\hline $\operatorname{Area}(\mathrm{A})-$ unit $^{2}$ & 0.1429 & 0.1122 & 0.1053 & 0.1196 & 0.1167 & 0.1159 \\
\hline $\begin{array}{l}\text { Percentage Change } \\
\text { in Area }(\mathbf{A} \%)\end{array}$ & 0 & -21.48 & -26.31 & -16.31 & -18.33 & -18.89 \\
\hline
\end{tabular}


Varying friction coefficient on pressure distribution... 25

slip points and compares favorably with the modified Avitzur model between the no-slip and the exit points.

\section{REFERENCES}

Andersson, S., Söderberg, A. and Björklund, S., (2007). Friction models for sliding dry, boundary and mixed lubricated contacts. Tribology International, 40(4): 580-587.

Avitzur, B. (1964). An upper-bound approach to cold-strip rolling. Journal of Engineering for Industry, 86(1):31-45.

Beik, H. A. A. and Dehghani, K.(2008). Irregularity in Friction Hills during the Cold Rolling of Materials. International Journal of $M a-$ terial Forming, 1(1): 343-346.

Davis, F., Andoh, P. Y., Sackey, M. N. and Owusu-Ofori, S. P. (2014). Assessment of friction between a rolling cylindrical element and a deformable flat surface. Journal of Science and Technology, 34(2): 26-34.

Davis, F., Sackey, M. N., Andrews, A. and Owusu-Ofori, S. P.( 2017). Realistic friction coefficient model between a rolling cylindrical element and a deformable flat surface. Tribology International, 109: 252-257.

Dieter ,G. E. (1976). Mechanical Metallurgy, Materials Science and Engineering Series, McGraw-Hill Book Company, New York, $2^{\text {nd }}$ Edition, Pp. 613-614

Gosh, A and Mallik, A. K. (1986). Manufacturing Science, Ellis Horwood Limited, Chichester, Pp. 112-115

Groover, M. P. (2007). Fundamentals of Modern Manufacturing: Materials Processes, and Systems. John Wiley \& Sons.

Hill, R. (1963). A general method of analysis for metal-working processes. Journal of the Mechanics and Physics of Solids, 11(5) : 305 $-326$.

Lenard, J. G. (2004), "The Effect of Roll Roughness on the Rolling Parameters during Cold Rolling of an Aluminum Alloy." Journal of Materials Processing Technology, 152: 144-153.

Murthy, H. and Vadivuchezhian, K. (2017). Estimation of friction distribution in partialslip contacts from reciprocating full-sliding tests. Tribology International, 108:164-173.

Roberts, C. D., (1997), "Mechanical Principles of Rolling." Journal of Iron and Steel, 24 : 113-114.

Tieu, A. K. and Liu, Y. J.(2004). Friction variation in the cold-rolling process. Tribology International, 37(2): 177-183.

\section{NOMENCLATURE}

$\begin{array}{llll} & & & \text { Friction Coefficient } \\ h_{0} & \text { Initial Slab Thickness }(\mathrm{mm}) & P_{r} & \text { Roll Separation Force }(\mathrm{N}) \\ h_{f} & \text { Final Slab Thickness }(\mathrm{mm}) & \bar{\sigma} & \\ R_{0} & \begin{array}{l}\text { Roll Radius }(\mathrm{mm}) \\ \text { Change in Roll Angle (radians) }\end{array} & R^{\prime} & \text { Average Flow Stress }\left(\mathrm{N} / \mathrm{mm}^{2}\right) \\ d \theta & \text { Roll Angle (radians) } & \sigma_{y} & \text { Radius of Flattened Roll }(\mathrm{mm}) \\ \theta & \text { Roll Pressure at Roll Angle } & \sigma_{x b} & \text { Yield Strength }\left(\mathrm{N} / \mathrm{mm}^{2}\right) \\ P_{\theta} & \text { Friction Force (Ibf) } & \sigma_{x f} & \text { Back Tension }\left(\mathrm{N} / \mathrm{mm}^{2}\right) \\ F & \text { Normal Pressure }(\mathrm{Ibf}) & N_{r} & \text { Length of Rolled Part }(\mathrm{km}) \\ P & \text { Normal Stress }\left(\mathrm{N} / \mathrm{mm}^{2}\right) & K & \text { Shear Yield Strength } \\ \sigma & & & \end{array}$

